\title{
Design Guidelines for Creating Mobile Language Learning Applications
}

\author{
https://doi.org/10.3991/ijim.v12i3.8153 \\ F. Fazeena Jamaldeen $\left.{ }^{\square}\right)$, K. P. Hewagamage, Y. Ekanayaka \\ University of Colombo, Colombo, Sri Lanka \\ jffazeena@gmail.com
}

\begin{abstract}
Mobile devices have proven to be an appropriate tool which expands the horizons of learning beyond the classroom through means of flexibility and portability. Throughout this study, the authors have worked with a set of design guidelines which were derived from the literature. The artifact developed considering these design guidelines has been evaluated among various user groups for better understanding of m-learning as a tool to support English Language Learning. Findings of these evaluations have been used to improve the design guidelines. The authors also identify the effectiveness of mobile learning as a supporting medium of learning and as a primary medium of learning among different learner groups, which is another outcome of this study.
\end{abstract}

Keywords - mobile learning, effectiveness, design guidelines, English language learning.

\section{Introduction}

In the present growing field of education, mobile learning has been found to be one of the major developing areas through the new learning experience provided along with mobile technologies. The growing body of research in the area of mobile language learning indicates the acceptance of m-learning among the community [1] [2] [3] [4]. Mobile learning also has been a topic discussed among researchers for the last 20 years and has encompassed a wide range of theories, concepts, designs, experiments and conclusions [5]. The power of mobile devices and advanced technologies have created ease of access to educational resources to learners. The increased mobile penetration and the capabilities of mobile devices [2] are evident as opportunities by the notion of mobile learning. The dramatic growth in the mobile usage and the penetration of smart phones in the society could be an opportunity for learning [5].

The authors find that the existing studies on m-learning are merely connected to the notion of designing m-learning in relation to an existing e-learning curriculum. Although m-learning has been experimented in many scenarios, there are only a handful of studies experimenting m-learning in Sri Lankan context [6] [7] [8] [9] [10]. Hence the authors try to research this area, which might be a guide for future researchers who explore the m-learning in similar context. 


\subsection{Research questions}

1. What are the factors to be considered in the process of implementing a mobile learning application based on an existing e-learning curriculum? Through this research question we try to identify the factors that needs to be taken into consideration while implementing an m-learning solution based on an existing e-learning course. Authors try to draw a set of design principle based on the literature. The design principles identified have been used throughout the artifact development and revised based on the findings of the evaluations.

2. How effective is mobile learning in the context of promoting English language learning as a supporting and a primary medium of learning? This research question is focused on finding out the effectiveness of m-learning among the target users, as a primary as well as a supporting medium of learning. Addressing this research question, we study the effectiveness based on the learner engagement, learner attitude and perceived usefulness.

\subsection{Mobile4E - The artefact used for this study}

Our previous study [11] proved the need of a mobile based learning application. Considering the user requirements and mobile application design guidelines, a mobile based learning application (Mobile4E) [12] [13] was designed and developed. The content of this course was extracted from the 'English for All (EFA)' an online learning course [14] which was designed by the Ministry of Education, Sri Lanka, targeting the school leavers. Mobile4E applications contained three different apps according to the user difficulty levels namely; Mobile4 elementary, Mobil4E intermediary and Mobil4E advanced. The main components of each of the applications were as follows:

Lessons: The lessons are created based on the existing EFA modules. The lessons include text, flash animations, videos and audio lessons. Additional bookmarking facility is included to bookmark the lessons as favourites for later references.

Activities: The activities are displayed following each lesson in order to assist the learning activities and designed in a way that it enhances the learning outcome of the students, rather than testing their knowledge. The application consists of different types of learning activities such as multiple choice questions (MCQs), fill in the blanks, drag and drop questions, tap on the words and structured questions with short answers.

Forum: The forum activities are designed with the aim of enhancing the learnerlearner interaction through the application. Each participant is able to post a message to the forum, where all others are able to view it and comment on it. The forum topics are related to the lesson content and are linked to the activities.

Scorecard: The scorecard option displays the number of activities completed with correct answers in each lesson. This provides an overall idea of the performance of the learner, hence it motivates the learner. 

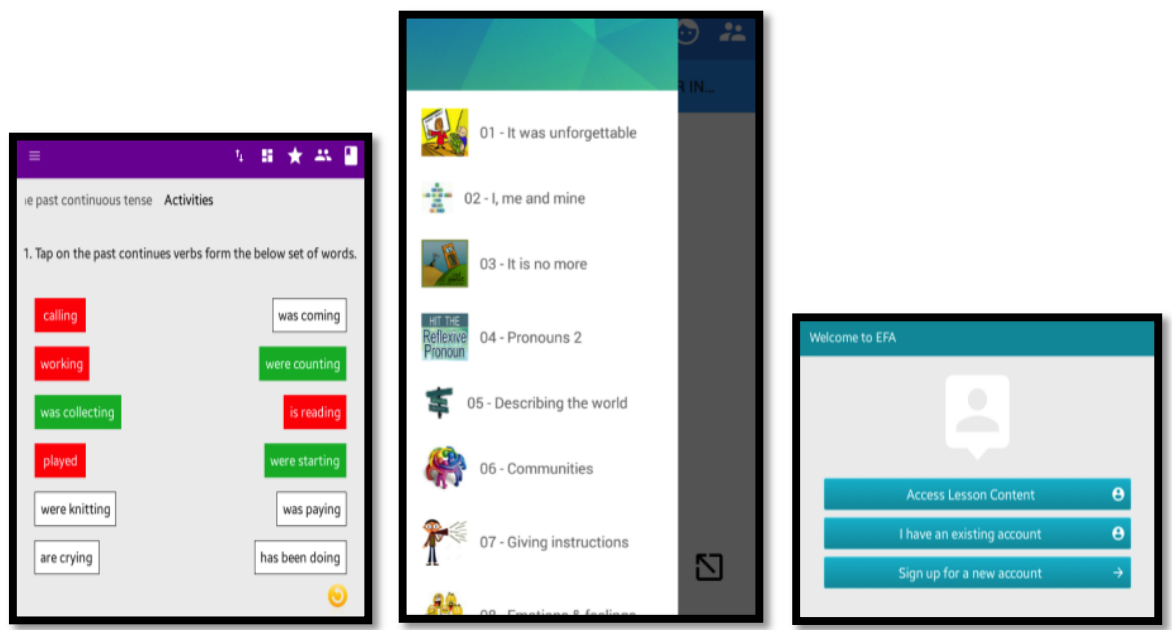

Fig. 1. Screenshots from Mobile4E

\section{The initial design principles}

Based on the notion of recreating the content for mobile applications in a blended learning environment, we studied the design principles already found in literature. Although we were looking for the design considerations of creating m-learning in blended environments, we found that most of the common m-learning design principles also apply. Hence, following design considerations extracted from the literature are explained. When carefully reviewing them, it is evident that the literature is focusing on designing the m-learning artefact without considering the blend of different learning methods.

Table 1. Design Principles for Developing m-Learning Content

\begin{tabular}{|c|c|c|c|}
\hline Category & $\begin{array}{l}\text { Design Princi- } \\
\text { ples }\end{array}$ & Key points & Authors \\
\hline \multirow{5}{*}{$\begin{array}{l}\text { Technological } \\
\text { facets of de- } \\
\text { signing m- } \\
\text { learning }\end{array}$} & $\begin{array}{l}\text { Design the inter- } \\
\text { face to compen- } \\
\text { sate small screen }\end{array}$ & $\begin{array}{l}\text { Information needs to be presented in pieces; Usage of } \\
\text { Zooming and floating panels; Use of audio podcasts. }\end{array}$ & {$[1] ;[15]$} \\
\hline & \begin{tabular}{|l|l|} 
Navigational \\
strategies
\end{tabular} & $\begin{array}{l}\text { Strategies to move back and forth; Minimized scrolling; } \\
\text { Usage of zooming and floating panels. }\end{array}$ & $\begin{array}{l}{[1] ;[15] ;} \\
{[16]}\end{array}$ \\
\hline & $\begin{array}{l}\text { Consider variety } \\
\text { of elements }\end{array}$ & $\begin{array}{l}\text { Use of multimedia messages; Design elements to assist } \\
\text { comprehension and memory; Use mobile friendly and light } \\
\text { weighted; In a blended environment the multimedia ele- } \\
\text { ments can be related to the e-learning course. }\end{array}$ & $\begin{array}{l}{[17] ;} \\
{[15] ;} \\
{[18]}\end{array}$ \\
\hline & $\begin{array}{l}\text { Spontaneous } \\
\text { access of materi- } \\
\text { als }\end{array}$ & $\begin{array}{l}\text { Location independent access; Time independent access; } \\
\text { Place the materials in electronic repository. }\end{array}$ & \begin{tabular}{|l}
{$[19][17]$} \\
{$[1][20]$} \\
{$[16]$}
\end{tabular} \\
\hline & $\begin{array}{l}\text { Support multiple } \\
\text { device types }\end{array}$ & $\begin{array}{l}\text { Use different means of learning such as stable technologies. } \\
\text { Ex: Desktop computers and interactive whiteboards }\end{array}$ & [19] \\
\hline Pedagogical & Keep the infor- & Present the information in an organized manner; Simplify & [1] [20] \\
\hline
\end{tabular}




\begin{tabular}{|c|c|c|c|}
\hline \multirow{2}{*}{$\begin{array}{l}\text { facets of de- } \\
\text { signing m- } \\
\text { learning }\end{array}$} & mation organized & the information; Chunking and grouping; & {$[17]$} \\
\hline & $\begin{array}{l}\text { Multiple peda- } \\
\text { gogy/ activities }\end{array}$ & $\begin{array}{l}\text { Design in a way to accommodate different learning styles } \\
\text { and characteristics; Include multiple pedagogical exercises } \\
\text { and activities }\end{array}$ & $\begin{array}{l}{[1] ;[18]} \\
{[19]}\end{array}$ \\
\hline \multirow{2}{*}{$\begin{array}{l}\text { Human can- } \\
\text { tered facets of } \\
\text { designing m- } \\
\text { learning }\end{array}$} & $\begin{array}{l}\text { Design for per- } \\
\text { sonalized learn- } \\
\text { ing }\end{array}$ & $\begin{array}{l}\text { Comprise the means of personalization; Allow learners to } \\
\text { explore and select information to cater to personal needs; }\end{array}$ & $\begin{array}{l}{[21][1]} \\
{[19][17]} \\
{[22]}\end{array}$ \\
\hline & $\begin{array}{l}\text { Incorporate } \\
\text { Collaborative } \\
\text { activities }\end{array}$ & $\begin{array}{l}\text { Development of community of practice, apprenticeships and } \\
\text { mentorships; Allow students to work in small groups. }\end{array}$ & $\begin{array}{l}{[17] ;[1]} \\
{[22][19] .}\end{array}$ \\
\hline
\end{tabular}

\section{$3 \quad$ Methodology}

\subsection{Design Based Research}

The whole of this research was carried out based on Design Based Research (DBR), as DBR has been proved as an appropriate research method in exploring possibilities for creating novel learning and teaching environments [23]. Reevs (2008) steps of DBR was used to determine the steps in this research [24] [25]. This paper addresses the third and fourth stage of Reeves model as explained below.

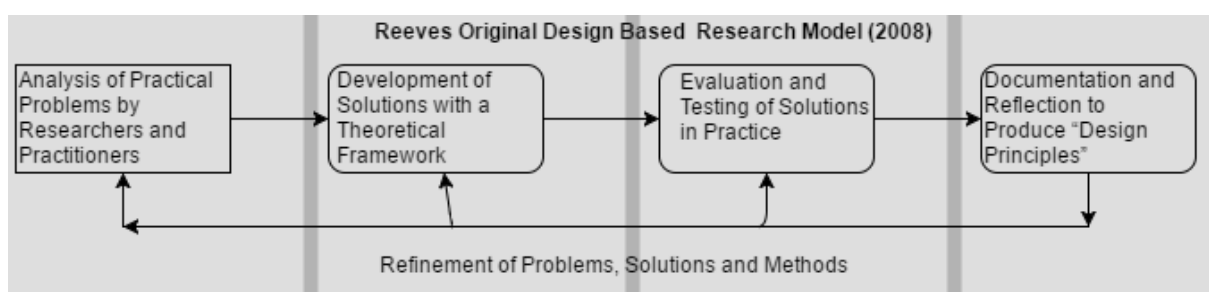

Fig. 2. The design based research (Tel Amiels and Reevs, 2008)

The third stage of the Reeve's (2008) methodology was about the evaluation and the testing phases associated to a research, which occurs after the development of solutions. This phase incurs the iterative cycles and refinements of solutions in practice [25]. The iterative nature of design-based research means that a single implementation is rarely sufficient to gather enough evidence about the success of the intervention and its effect on the problem situation [23]. In the case of this research, the authors present the evaluation using the case study approach. Different user groups were identified including experts and actual learners to ensure the validity of the study. As suggested by Herrington [22], few changes were made after the first cycle of evaluation carried out with the experts. The four cases are explained below.

a) Case 01: Evaluation with the experts: As suggested by [24], the first evaluation was carried out as a heuristic evaluation among the experts in order to get their feedback before introducing the artefact to the actual learners. The results revealed through this case study made the authors to revert back to the second stage of the methodology and carry out certain modifications. 
b) Case 02: Evaluation of the artefact as a supporting medium of learning: This phase of this research was associated to the second case study carried out with the actual learners introducing m-learning as a supporting medium of learning. Mlearning was introduced along with a formal course module in addition to the elearning and face to face learning methods.

c) Case 03: Evaluation of the artefact as a primary medium learning: This was the third case study, where the m-learning artefact was introduced as a primary medium of learning.

d) Case 04: Evaluation with UX experts: Although this stage was not initially planned, the research group got an opportunity to meet a group of UX specialists, where the participants were able to evaluate the artefacts and provide their feedback.

Based on the analysis of data collected from the 4 case studies, the improved design guidelines are presented as the contribution of this research.

\section{$4 \quad$ Findings and discussions}

\subsection{Case 01: Heuristic evaluation with the experts}

The heuristic evaluation was carried out with a set of subject matter experts and technical experts. Users were assigned to any one of the Mobile4E applications and requested to figure out any technical/ content related issues, while suggesting any improvements along with their general feedback about the application. Two separate workshops were carried out where the first one was with English Teachers, who were considered to be independent and not involved during the designing of the content of this application. There were 13 English teachers involved with the feedback and they preferred working in groups to come up with the content related feedback. Their general feedback was collected through unstructured interviews and observations. The technical evaluation carried out with the internal staff of University of Colombo School of Computing (UCSC) had 14 participants. Participants were provided with time to get their hands-on experience with Mobile4E and provide their feedback through a feedback questionnaire.

Findings and Analysis Both groups found this application as a possible successful self-learning material for students. More than $90 \%$ of the users found this app as a tool which motivates the learner to learn English through the mobile. It was noted that more than half of the users needed assistance in navigating through the app especially during the initial use. The users required assistance with the menu options and functionalities of the application. With respect to the color combinations and the images/ graphics used in the app, the users were happy with the multimedia elements and found the images and videos meaningful. Further, they stated that the time taken to load the application was less. However, few device dependent issues were reported. The videos were unable to playback on certain versions of Android operating systems, which needed consideration. Users also stated that they find the forum function useful 
and perceive it promote collaborative learning. Reviewers also found the bookmarking function very useful to store their favorite lessons for later use.

Few issues were indicated with respect to the structure of the content, where they suggested to re-organize the content in a meaningful way. Further, some users found the drag and drop function difficult, hence they suggested to redesign them. Suggestions were provided to increase the number of activities within each lesson. Few of the subject matter experts found that the Elementary level app needs to have more basic components, which should be easy to understand by a novice user. Content related issues such as spelling and grammar related issues were tracked and notified by the team.

Refinement of the solution This heuristic evaluation allowed the researchers to identify and correct content related issues and technical issues which were not tracked during the unit testing and system testing phase. As a result of this evaluation cycle the researcher had to again refine the solution in order to introduce it among the actual learners. According to Reeves (2008), it is usual to make changes and refine the solutions during the third stage of the Design Based Research [25]. Due to limited time and resource constrains, researchers could not do any major re-structuring and corrections. All content related small scale issues such as spelling and grammar corrections were done following the review of the subject matter experts. The technical issues which were spotted throughout the application was rectified as much as possible. The major issue which was addressed with the video playback needed redesigning which was rectified following this stage of evaluation.

\subsection{Case 02: Introducing the m-learning as a supporting medium of learning}

Learner profile When analyzing the learner profile data in the backend database table that belongs to G1, the authors found that there were 105 unique users who have registered to any one of the Mobile4E applications. They all were internal students who were enrolled to the university. There were 42 female students and 63 male students.

Further, the authors were able to gather data relevant to the screen resolutions accessed through the application throughout the study period. Google analytics was used to gather this data. Following screen captures shows the device screen resolutions accessed the application throughout the study period.

Learner engagement with Mobile4E The authors were able to track the general access patterns of the users including activities sand forum messages. All the data accept the forum messages were collected through the Google Analytics api. Due to the functional constraints in Google api, the forum messages were tracked through the backend database of the application. Learner engagement was monitored for 10 weeks as shown below. 


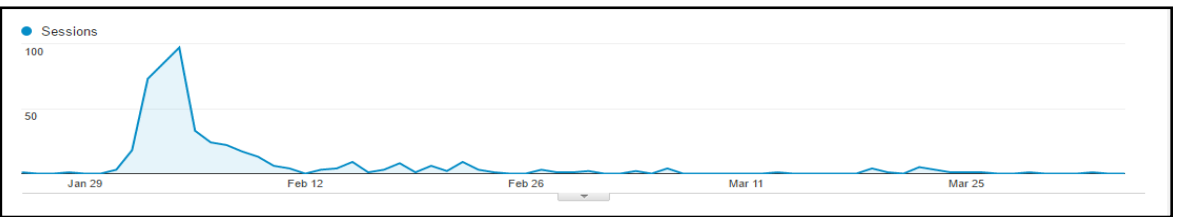

Fig. 3. Access to the elementary application: G1

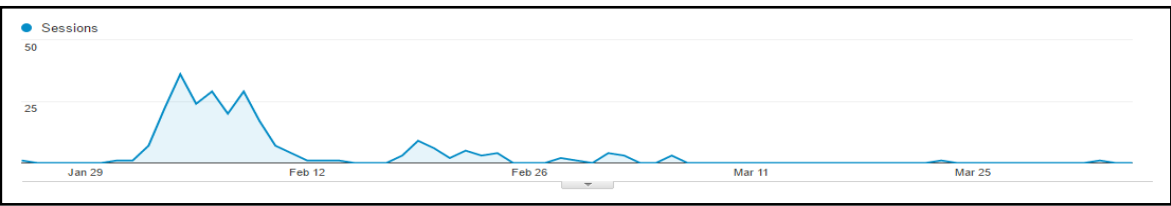

Fig. 4. Access to the intermediary application: G1

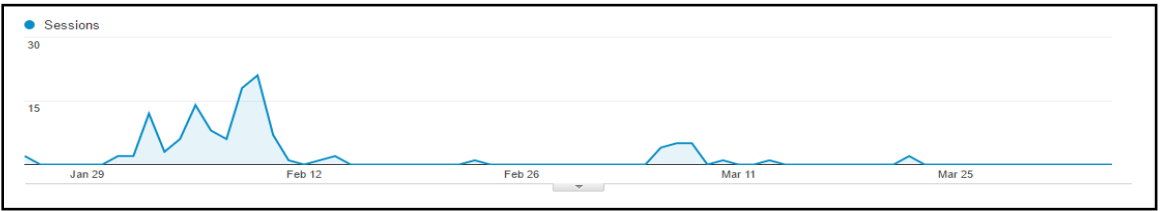

Fig. 5. Access to the advanced application: G1

The summery of all three access of the all three applications can be tabularized as below.

Table 1. Interaction summery

\begin{tabular}{|l|c|c|c|c|c|}
\hline \multicolumn{1}{|c|}{ Applications } & Users & Sessions & Screen views & $\begin{array}{c}\text { Screens/ } \\
\text { Session }\end{array}$ & $\begin{array}{c}\text { Average Session } \\
\text { Duration }\end{array}$ \\
\hline Elementary & 70 & 479 & 6,424 & 13.41 & $00: 07: 36$ \\
\hline Intermediary & 39 & 248 & 3,139 & 12.66 & $00: 08: 05$ \\
\hline Advanced & 34 & 124 & 1,469 & 11.85 & $00: 07: 48$ \\
\hline Total & 143 & 851 & 11,032 & 12.96 & \\
\hline
\end{tabular}

The total number of sessions associated to the study period was 851 , with 11,032 screens views. Further, from the above table it is visible that the users have spent considerable amount of time browsing the lessons. There were more users and sessions associated to the elementary application, with a declining number towards the advanced application. This shows that the students are more interested during the startup of the course along with a declining interest throughway. Also, it was revealed the first month of the course has a peak of access, with a declining pattern towards the end. This shows that the students have the motivation only during the introduction of the application and steps should be taken to retain the motivation of the students' throughout the whole course period. 
The authors further analysed the bounce rate of the applications during the visit of time. Bounce rate refers to the single-entry sessions, where the user visits only first page/ one page and returns back without browsing further [26]. Surprisingly, the bounce rate associated to the group $\mathrm{G1}$, was $0 \%$ across all three applications, which means that none of the students who belong to the group G1, has returned back only after accessing the first page. The students have visited at least one of the lessons pages inside the application.

Learner engagement with the activities. The activities were one of the main part of the artifact which gained priority after the lessons. As the general access pattern discussed previously provides an insight relevant to the lessons, the authors decided to seek more information related to the activities. As the application covered a wider scope, it was not significant to browse through the activities associated with each lessons. Hence, the authors retrieved the information related to the access to the pages named as 'activities' as a whole. Following screen captures shows the overall engagement with the activities.

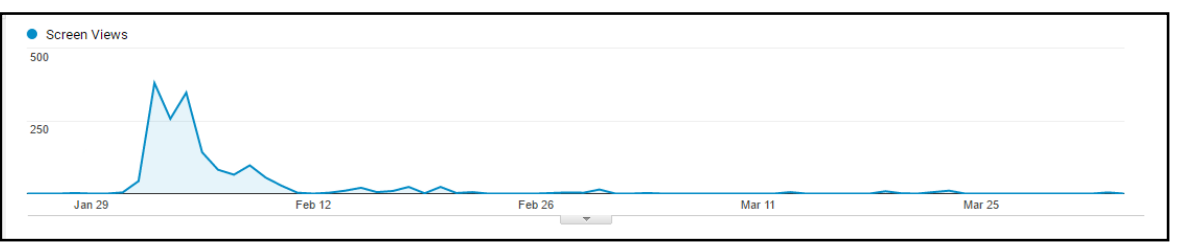

Fig. 6. Access to activities (Elementary)

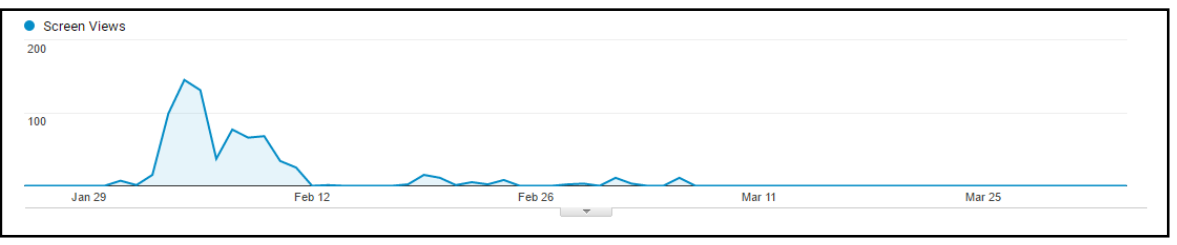

Fig. 7. Access to activities (Intermediary)

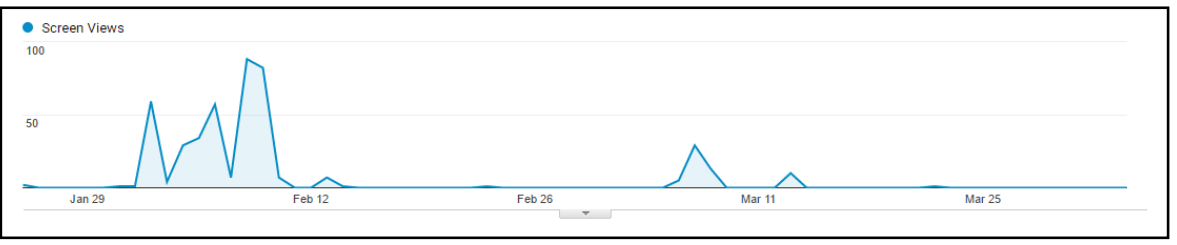

Fig. 8. Access to activities (Advanced)

The table below provides details of the access to the activities of all three applications as a whole. The percentage of the access of activities has been calculated against the total number of screen views. Out of the whole pages, the activity pages have gained 2,881 visits. This is $26.11 \%$ of the whole screen views. This shows that the students have accessed the activity page of almost all of the lessons because each 
lessons contained around 3-4 lesson pages and 1 activity page. Further noticing the time spent in the activity page is more than one minute, where the average time spent on the whole application was around 7-8 minutes. This depicts that the user has spent considerable amount of time browsing the activities.

Table 2. Access to activities

\begin{tabular}{|l|c|c|c|c|}
\hline \multicolumn{1}{|c|}{ Application } & $\begin{array}{c}\text { Number of Screen } \\
\text { views of activities }\end{array}$ & Screen views & Percentage & $\begin{array}{c}\text { Average time on } \\
\text { screen }\end{array}$ \\
\hline Elementary & 1,663 & 6,424 & $25.88 \%$ & $00: 01: 09$ \\
\hline Intermediary & 780 & 3,139 & $24.84 \%$ & $00: 01: 21$ \\
\hline Advanced & 438 & 1,469 & $29.81 \%$ & $00: 01: 19$ \\
\hline Total & 2,881 & 11,032 & $26.11 \%$ & $00: 01: 16$ \\
\hline
\end{tabular}

Engagement with the forum activities The forum part of the mobile application was developed with the aim of promoting collaborative learning among the students. The users were not allowed to create new forum topics, but allowed to post replies for each forum which were already created and linked with the lesson activities. Following table provides a summary of the number of valid responses typed by the students on the forums. 82 messages had been posted to the forums during the 10 weeks of time.

Table 3. Forum messages

\begin{tabular}{|l|c|}
\hline \multicolumn{1}{|c|}{ Application } & Number of replies \\
\hline Elementary & 44 \\
\hline Intermediary & 28 \\
\hline Advanced & 10 \\
\hline Total & 82 \\
\hline
\end{tabular}

Learner attitude towards m-learning A questionnaire was distributed among the participants at the end of the evaluation in order to assess the student attitudes towards MALL. Two Likert scale questions and one open ended question was included in the questionnaire in order to get the responses in various perspectives. Both Likert scale questions contained general attitude related statements and statements endorsing the usefulness of the application respectively. A paper based questionnaire was distributed among the participants during a formal lesson period, and 64 valid responses were received.

Following statements were provided in relation to the perception, and respondents were asked to rate each statement using a 1 (very poor) to 5 (excellent) scale. For reporting purpose, the responses were grouped into three naming Negative, Neutral and Positive. 
Table 4. Attitude towards MALL

\begin{tabular}{|l|c|c|c|}
\hline \multicolumn{1}{|c|}{ Statements } & Negative & Neutral & Positive \\
\hline Overall usefulness of the app & $3.1 \%$ & $29.7 \%$ & $67.2 \%$ \\
\hline Motivation to learn English through this app & $7.8 \%$ & $25 \%$ & $67.2 \%$ \\
\hline Flexibility provided by mobile & $1.6 \%$ & $14.3 \%$ & $84.1 \%$ \\
\hline Willingness to pay for mobile data usage & $8 \%$ & $33.3 \%$ & $58.7 \%$ \\
\hline
\end{tabular}

The summary of responses shown in Table 4 reveals that overall usefulness of this application was found to be positive. Although the learner engagement data gathered through google analytics shows declining motivation, the questionnaire shows increased motivation among students. When questioned about the cost, which is one of the concerns in adopting m-learning (Burstan, 2011), 59\% of G1 have provided a positive response showing their willingness to pay for the network charges incurred using the application and $33.3 \%$ provided a neutral response. Although more than half of the respondents have provided a positive response, still there is a significant number who considers the cost as an issue.

When considering the responses as a whole, it is visible that majority of the students who belong to $\mathrm{G} 1$ have provided positive responses.

Apart from the overall perception of the users, another Likert scale was issued in order to identify the usefulness of the application. The questionnaire consisted of structured statements in relation to the understandability of the lessons, navigation, structure, multimedia elements, interactivity and the effectiveness of the individual functions in the application. Users were requested to rate each statement using a 1 (very poor) to 5 (excellent) scale. For reporting purpose, the responses were grouped into three, namely, Negative, Neutral and Positive.

Table 5. Usefulness of the m-learning artifact

\begin{tabular}{|l|c|c|c|}
\hline \multicolumn{1}{|c|}{ Statements } & Negative & Neutral & Positive \\
\hline Understandability of the lessons & $3.1 \%$ & $17.2 \%$ & $79.7 \%$ \\
\hline Ease of navigation & $12.9 \%$ & $22.6 \%$ & $64.5 \%$ \\
\hline Appropriateness of the colour combinations & $3.1 \%$ & $28.1 \%$ & $68.8 \%$ \\
\hline Structure of the lessons & $1.6 \%$ & $17.2 \%$ & $81.3 \%$ \\
\hline Meaningfulness of the images/ videos used & $1.6 \%$ & $21.9 \%$ & $76.6 \%$ \\
\hline Effectiveness of the discussion forum & $15.6 \%$ & $28.1 \%$ & $56.3 \%$ \\
\hline Usefulness of bookmarking function & $12.7 \%$ & $31.7 \%$ & $55.6 \%$ \\
\hline Interactivity of the activities & $4.7 \%$ & $15.6 \%$ & $79.7 \%$ \\
\hline
\end{tabular}

According to the above presented statements, it is visible that with respect to the understandability of the lessons, the respondents showed a strong positive perception. Majority of the users have found the application easy to navigate and lessons well structured. With respect to the colour combinations and multimedia elements included in the application, majority of the respondents have provided a positive response. Although more than half of the users have found the discussion forums and the bookmarking facilities useful, still there is a considerable amount of neutral responses. Around $80 \%$ of the users have found the activities interactive. As a whole, it is 
visible that majority of the users have provided positive responses to the statements presented, which shows a promising value of m-learning among the selected user group.

\subsection{Case 03: Introducing the m-learning as a primary medium of learning}

Learner profile In G2, there were 118 (30 female and 88 male) unique users who were registered with at least one application of Mobile4E within the given period. When analyzing there age groups, we found that 8 users were $15-20$ years old, 62 users were in the age group of 21-25, and 30 belonged to the age group of 26-30, while 11 were 31-35 years and the remaining 7 belonged to the age group of 36-40. This shows that majority of the users were below 30 years.

Learner engagement with Mobile4E Similar to the previous study, the interaction patterns of this learner group was also tracked using Google analytics api. Different tracking IDs were used among the two different groups (G1 and G2) and among each application. General access patterns, engagement with the activities and forum messages also were monitored. Similar to the previous group, Google analytics was monitored for 10 weeks throughout the period of evaluation.

The following screenshots taken from Google analytics shows the overall access pattern of G2 during the study period over all three applications.

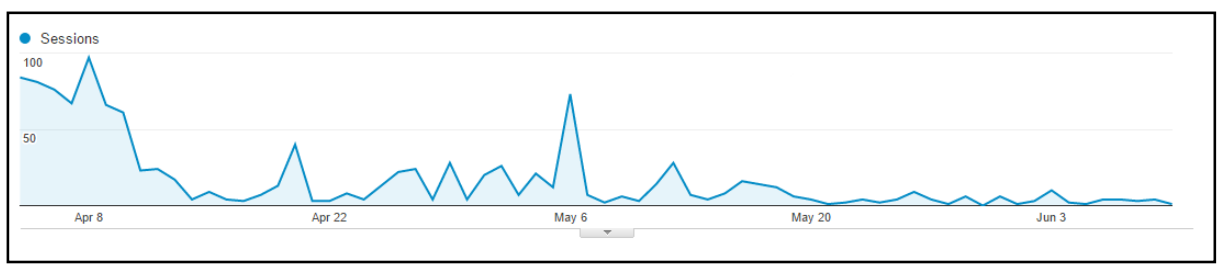

Fig. 9. Access to the elementary application: G2

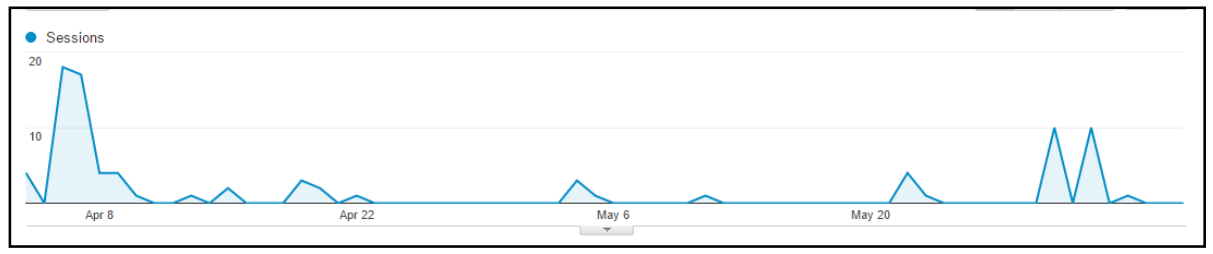

Fig. 10.Access to the intermediary application: G2

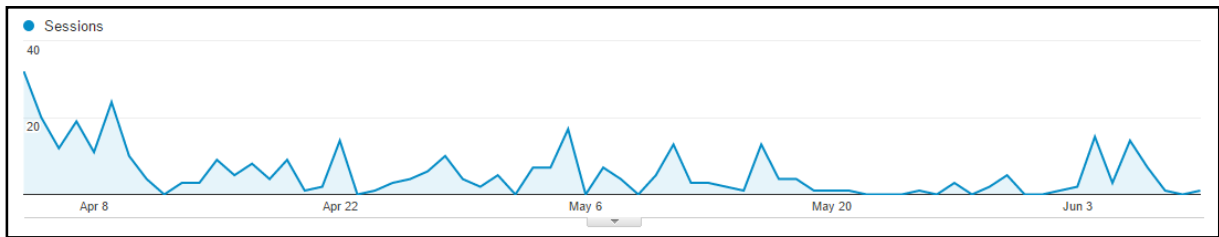

Fig. 11.Access to the advanced application: G2 
The summery of all three access of the all three applications can be tabularized as below.

Table 6. Interaction summary of G2

\begin{tabular}{|l|c|c|c|c|c|}
\hline \multicolumn{1}{|c|}{ Application } & Users & Sessions & Screen views & Screens/ Session & Average Session Duration \\
\hline Elementary & 100 & 1,151 & 4,507 & 3.92 & $00: 00: 34$ \\
\hline Intermediary & 15 & 88 & 334 & 3.80 & $00: 00: 43$ \\
\hline Advanced & 37 & 373 & 1,359 & 3.64 & $00: 00: 51$ \\
\hline Total & 152 & 1,612 & 6200 & 3.84 & $00: 00: 43$ \\
\hline
\end{tabular}

According to the above table it is visible that $\mathrm{G} 2$ had more users than the previous group. The number of sessions during the period of G2 have been 1612 with 6200 screen views. The average screens per session in this group was 3.84. This shows that although students of this group have accessed the application more times, they have not gone through the lessons. Further going through the above table, it is noticeable that the student have spent a minimal time through the application which is around 43 seconds.

The access pattern of the G2 has the peak of session in the beginning, but still few sessions throughout the study period, which shows an inconsistent pattern. The authors further analysed the bounce rate of this user group which is presented below.

Table 7. Bounce rate of $\mathrm{G} 2$

\begin{tabular}{|c|c|}
\hline Application & G2 \\
\hline Elementary & $11.54 \%$ \\
\hline Intermediary & $62.45 \%$ \\
\hline Advanced & $10.40 \%$ \\
\hline Average & $26.48 \%$ \\
\hline
\end{tabular}

This shows that more than quarter of G2 students has accessed only the first page of the application and returned back. When looking into the bounce rate of each applications, it was noted that the intermediary application had a higher bounce rate compared to the other two applications.

Learner engagement with the activities As presented in the previous cycle of this study, the authors were able to retrieve data related to the access patterns to the pages named as 'activities' as a whole. Following screen captures shows the overall engagement with the activities.

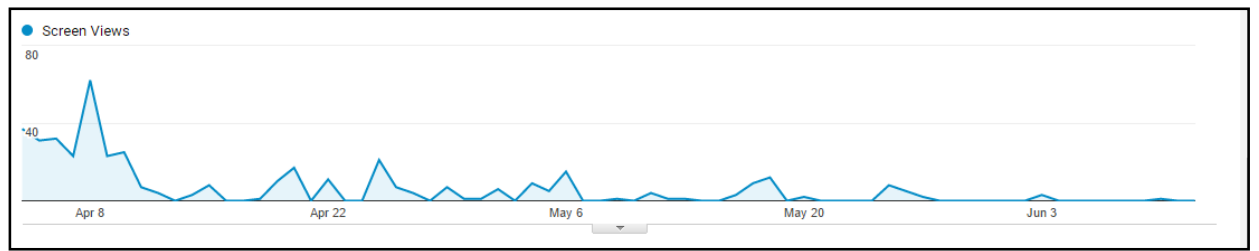

Fig. 12.Access to the elementary application activities: G2 


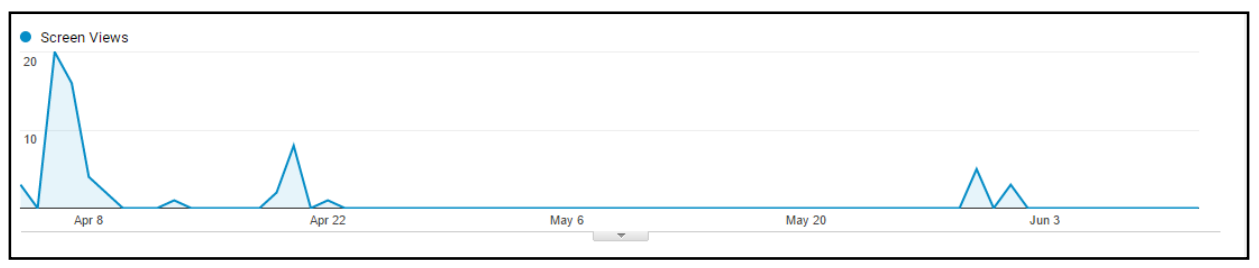

Fig. 13.Access to the intermediary application activities: G2

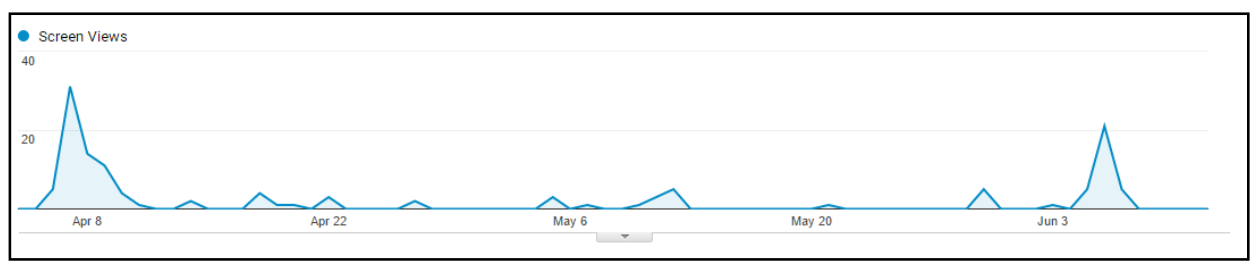

Fig. 14. Access to the advanced application activities: G2

Table 8. Interaction with activities (G2)

\begin{tabular}{|l|c|c|c|c|}
\hline \multicolumn{1}{|c|}{ Application } & $\begin{array}{c}\text { Number of Screen views } \\
\text { of activities }\end{array}$ & Screen views & Percentage & $\begin{array}{c}\text { Average time on } \\
\text { screen }\end{array}$ \\
\hline Elementary & 422 & 4,507 & $9.36 \%$ & $00: 00: 25$ \\
\hline Intermediary & 65 & 334 & $19.46 \%$ & $00: 00: 17$ \\
\hline Advanced & 130 & 1,359 & $9.56 \%$ & $00: 01: 01$ \\
\hline Total & 617 & 6,200 & $9.95 \%$ & $00: 00: 34$ \\
\hline
\end{tabular}

Table 8 provides details of the access to the activities of all three applications as whole. The percentage of the access of activities has been calculated against the total number of screen views. Out of the whole pages, the activity pages have gained only 617 visits. This is $9.95 \%$ of the whole screen views. This shows that the student has not accessed the activity page of all the lessons. Because almost all the lessons contained around 3 to 4 pages. Further noticing the time spent in the activity page varies among three applications. Although the average of time spent on each activity is around 34 seconds, the average time spent on the whole application was 43 seconds. This depicts that activities have captured more time compared to the lessons.

Engagement with the forum activities Similar to G1, this group also had forum activities embedded. Following table provides a summary of the number of valid responses typed by the students on the forums.

Table 9. Forum replies

\begin{tabular}{|l|c|}
\hline \multicolumn{1}{|c|}{ Application } & Number of replies \\
\hline Elementary & 22 \\
\hline Intermediary & 01 \\
\hline Advanced & 02 \\
\hline Total & 25 \\
\hline
\end{tabular}


Comparing to the previous group, learners have spent only little amount of effort to put through new forum posts. Further, the elementary, which was considered to be the starting point has received more forum posts compared to the others. This once again validates the declining motivation throughout the applications.

Learner attitude towards m-learning A questionnaire was distributed among the participants of this group as well in order to assess the student attitudes towards MALL. The authors were able to gather 31 valid responses from the learner group.

Following statements were provided in relation to the perception, and respondents were asked to rate each statement using a 1 (very poor) to 5 (excellent) scale which were grouped into three for reporting.

Table 10.

Attitude towards m-learning

\begin{tabular}{|l|c|c|c|}
\hline \multicolumn{1}{|c|}{ Statements } & Negative & Neutral & Positive \\
\hline Overall usefulness of the app & $22.6 \%$ & $19.4 \%$ & $58.1 \%$ \\
\hline Motivation to learn English & $32.3 \%$ & $19.4 \%$ & $48.4 \%$ \\
\hline Flexibility provided by mobile & $19.4 \%$ & $25.8 \%$ & $54.8 \%$ \\
\hline Willingness to pay for mobile data & $9.7 \%$ & $41.9 \%$ & $48.4 \%$ \\
\hline
\end{tabular}

Although most of the leaners were found to be advocates of m-learning, there was also a considerable number of opponents in G2. Around 55\% of G2 have agreed that such applications provide the flexibility to learn irrespective of the location and time. When questioned about the cost, which is one of the concerns in adopting m-learning [27] , 48\% of G2 have provided a positive response showing their willingness to pay for the network charges incurred using the application. When considering the responses as a whole, it is visible that the respondents of $\mathrm{G} 2$ have provided responses which have a spread of Negative, neutral and positive with less differences.

\section{Perceived usefulness of mobile assisted language learning}

Table 11. Perceived usefulness of m-learning

\begin{tabular}{|l|c|c|c|}
\hline \multicolumn{1}{|c|}{ Statements } & Negative & Neutral & Positive \\
\hline Understandability of the lessons & $32.3 \%$ & $22.6 \%$ & $45.2 \%$ \\
\hline Ease of navigation & $48.4 \%$ & $12.9 \%$ & $38.7 \%$ \\
\hline Appropriateness of the colour combinations & $35.5 \%$ & $22.6 \%$ & $41.9 \%$ \\
\hline Structure of the lessons & $32.3 \%$ & $16.1 \%$ & $51.6 \%$ \\
\hline Meaningfulness of the images/ videos & $35.5 \%$ & $19.4 \%$ & $45.2 \%$ \\
\hline Effectiveness of the discussion forum & $35.5 \%$ & $16.1 \%$ & $48.4 \%$ \\
\hline Usefulness of bookmarking function & $35.5 \%$ & $19.4 \%$ & $45.2 \%$ \\
\hline Interactivity of the activities & $35.5 \%$ & $16.1 \%$ & $48.4 \%$ \\
\hline
\end{tabular}

Questions were included with the aim of identifying the perceived usefulness of this application among the users. A Likert scale was issued with statements related to usefulness of the application. When questioning about the understandability of the lessons, G2 has respondents who are in all three positions. Around half of the G2 
users $(48.4 \%)$ have found the navigation difficult. Similarly, around $32 \%$ of the G2 users have found the structure of the lessons poor, while as half of them have found it good $(51.6 \%)$. The similar pattern exists in other statements as well. The statement issues with regard to the colour combinations and multimedia elements included in the application, shows that more of the G2 respondents have found it good, compared to those who have provided a negative response. The pattern of the responses remain the same throughout the other statements issued relevant to the components of the application as well.

Interpretation of the findings The evaluation carried out with the actual learners, provided more valuable insights with respect to implementing m-learning. Through the data collected form the google analytics it was found that the group who had access to Mobile4E apps as a part of their formal course in a blended learning environment (G1) along with face to face and e-learning environment had spent more time browsing the application. It was noticed that none of them had left the application after browsing only the landing page. But, the pattern of usage was declining after reaching the peak access during first few weeks of the course. This implies that certain measures should be taken in order to keep the learners engaged with the application, hence the need arises to study the motivational aspects of mobile based learning applications. Further, the results of the questionnaires showed that G1 had a strong positive attitude towards mobile learning compared to G2. Although higher percentage of G2 students had a positive attitude towards m-learning, there were considerable percentage of opponents as well. But it is questionable whether the respondents of G2 had enough experience with the application before providing their feedback, as the analytics shows less engagement of G2 with Mobile4E. There can be number of reasons for less engagement of G2 users with the application, which needs to be further investigated.

The results of the study conducted with the two groups of actual users (Case 2 and Case 3) helps us to answer our $2^{\text {nd }}$ research question. The study reveals that an application created based on an e-learning curriculum could be successful when it is implemented along with the eLearning course in a formal environment.

\subsection{Case 04 : Evaluation with UX experts}

This final stage of evaluation was carried out with a set of user experience (UX) designers at the Stockholm University of Sweden. Out of the group, there were two experts who were willingly contributing with their suggestions. User 1 was a $\mathrm{PhD}$ student working with UX designing and User 2 was an academic. Feedback was gathered through a one to one session between the development team of Mobile4E and the UX team. Data gathering techniques were unstructured interviews and observations.

Findings and Analysis User 1 found the content of the application to be bulky and suggested to simplify the content much as possible. Suggestions were provided to include one activity per screen, have the activities more action oriented, enhance the navigations by including more buttons to the application. Meanwhile the reviews of user 2 was to make the elementary level more basic that a learner who hasn't learnt English could understand. Further feedback was given to enhance the navigation. It 
was observed that both the users were lacking experience with android phones as they were looking for a 'back' button within the application itself. Further the target user group for this application would be the school leavers who have basic English knowledge who could understand by reading. Through a thematic analysis it was revealed that two key points highlighted in this case was "simplifying the content' and 'enhancing the navigation'. Considering these factors, the artifact was refined for further evaluation and the design guidelines were improved as discussed in the next section.

\section{$5 \quad$ Refined design guidelines}

Unlike quantitative studies, DBR studies do not produce measurable results. However, they provide rich descriptions of the contexts in which the studies occurred, the challenges of implementation, the development processes involved in creating and administrating the interventions, and the design principles that emerged. Compiling the findings of this study throughout various phases, the authors have revisited the design principles for improvement. The following table shows the refined design principles summarized.

Table 12. Refined designed principles

\begin{tabular}{|c|c|c|}
\hline Category & Design guidelines & \\
\hline \multirow{6}{*}{$\begin{array}{l}\text { Technological } \\
\text { facets of designing } \\
\text { m-learning }\end{array}$} & $\begin{array}{l}\text { Design the interface } \\
\text { to compensate small } \\
\text { screen }\end{array}$ & $\begin{array}{l}\text { Present information in pieces; Constant font sizes across } \\
\text { lessons; Dynamic font sizes according to screen size; Zooming } \\
\text { functions; Use of video and audio podcasts. }\end{array}$ \\
\hline & $\begin{array}{l}\text { Navigational strate- } \\
\text { gies }\end{array}$ & $\begin{array}{l}\text { Use of zooming and floating panels; Strategies to move back } \\
\text { and forth; Minimised scrolling; User guide for navigation; } \\
\text { Knowledge of current position in the app; Navigation drawers; } \\
\text { Buttons irrespective of devices. }\end{array}$ \\
\hline & $\begin{array}{l}\text { Consider variety of } \\
\text { elements }\end{array}$ & $\begin{array}{l}\text { Interactive elements (e.g., buttons, hot-spots, roll-overs, or } \\
\text { sliders); Use mobile friendly and light weighted format for } \\
\text { images, audio and videos; Same resolutions for all videos } \\
\text { across the app; Options to play videos in full screen; Different } \\
\text { colours and sound as feedback; In a blended environment } \\
\text { relate the multimedia elements to the e-learning course. }\end{array}$ \\
\hline & $\begin{array}{l}\text { Spontaneous access } \\
\text { of materials }\end{array}$ & $\begin{array}{l}\text { Location and time independent access; Lightweight materials } \\
\text { embedded in the app independent from the internet access. }\end{array}$ \\
\hline & $\begin{array}{l}\text { Support multiple } \\
\text { device types }\end{array}$ & $\begin{array}{l}\text { Accommodate various device properties such as operating } \\
\text { systems and screen sizes. }\end{array}$ \\
\hline & $\begin{array}{l}\text { Consider visual } \\
\text { overload }\end{array}$ & Standardized layout and colours across application. \\
\hline \multirow{3}{*}{$\begin{array}{l}\text { Pedagogical facets } \\
\text { of designing m- } \\
\text { learning }\end{array}$} & $\begin{array}{c}\text { Keep the information } \\
\text { organized }\end{array}$ & $\begin{array}{l}\text { Chunk the information into smaller portions; Have the content } \\
\text { simpler; One activity per screen; Creating smaller applications }\end{array}$ \\
\hline & $\begin{array}{l}\text { Multiple pedagogy/ } \\
\text { activities }\end{array}$ & $\begin{array}{l}\text { Design to accommodate different learning styles; Multiple } \\
\text { types of activities; Options to redo activities; Immediate } \\
\text { feedback; }\end{array}$ \\
\hline & $\begin{array}{l}\text { Design for supporting } \\
\text { medium of learning }\end{array}$ & Have m-learning as a part of the whole course. \\
\hline
\end{tabular}




\begin{tabular}{|c|c|c|}
\hline \multirow{3}{*}{$\begin{array}{l}\text { Human centred } \\
\text { facets of designing } \\
\text { m-learning }\end{array}$} & $\begin{array}{l}\text { Design for personal- } \\
\text { ized learning }\end{array}$ & $\begin{array}{l}\text { Personalization through the application; personalization } \\
\text { through the device. }\end{array}$ \\
\hline & $\begin{array}{l}\text { Incorporate Collabo- } \\
\text { rative activities }\end{array}$ & $\begin{array}{l}\text { Development of community of practice, apprenticeships and } \\
\text { mentorships; Allow students to work in small groups. }\end{array}$ \\
\hline & $\begin{array}{l}\text { Design for learner } \\
\text { motivation }\end{array}$ & Current completion status; Game based learning. \\
\hline
\end{tabular}

\subsection{Technological facets of designing m-learning}

Design the interface to compensate small screen Mobile devices have smaller screen compared to the resources used in other means of learning such as computer screens and printed handouts which makes the design of mobile applications challenging. Following design guidelines are drawn up to support this design principle.

a) Present information in small pieces: Users will be spending only a little amount of time to browse the lessons through the mobile device, probably while accessing some other tasks in the device. Hence it is vital to present the lessons in a meaningful way in the tiny screen, where the information should be presented in small chunks. This reconfirms the previous findings that at the interface must be graphical and must present between five and nine chunks of information on the screen to prevent information overload in short-term memory $[1,15]$.

b) Use of audio/ video podcasts: According to [15], usage of audio podcast would be a much better task with the affordance of a mobile device. Throughout this study it was validated the use of video podcasts is also another option when it comes to presenting lessons in a restricted space.

Navigational strategies Since the information is presented in a small screen, it is essential to consider the navigational strategies during the design. This was validated especially through the $1^{\text {st }}$ and $4^{\text {th }}$ cases of our study.

a) Use techniques to ease navigation: Zooming and floating panels are two strategies which could be used to maximize the use of small screen [15]. Strategies such as navigational drawer and tab views will be more suitable for a mobile based application.

b) Strategies to move back and forth: The interface must use navigational strategies to allow learners to move back and forth [1]. Having tab views which allows users to move back by swiping will allow users to access more information within the limited screen.

c) Minimised scrolling: Having the information chunked into a smaller screen might create blank spaces in larger mobile screens. Because mobile screens vary in sizes. It is important to have the content marginally where users with tiny screens will have to go through a little bit of scrolling.

Consider variety of elements An m-learning solution should comprise variety of stimulus to assist comprehension and memory [17]. Having variety of multimedia elements will help learners to remember what they learn. We came up with following design guidelines to support captioned design principle. 
a) Use of interactive multimedia elements: Interactive elements (e.g., buttons, hotspots, roll-overs, or sliders) when integrated in a learning object should provide immediate feedback to the learner [15]. Meanwhile, it is also essential to consider the cognitive overload and distraction created by too much of elements in the screen. Hence, a balance among the elements is required to be maintained. Using similar shape of icons throughout the applications would help a constant flow.

b) Mobile friendly and light weighted elements: Images could be saved in PNG format and the videos should be incorporated in mobile friendly format (mp4) and light weighted. The length of the videos/ audios needs to be maintained short.

c) Have the elements related to the e-learning environment: This guideline would be specially applied for mobile applications created based on the e-learning course. In such cases the multimedia elements could be related to the e-learning course.

d) Design elements for feedbacks: The feedback on activities could be visually highlighting in order to enhance the problem based learning. Contrasting colours for right and wrong answers and having audio feedback will increase the interactivity.

Spontaneous access of materials One of the main advantages of m-learning is the portability of the mobile devices [1] [4]. Taking advantage of this feature, it is important to design the learning application irrespective of time and location.

a) Location independent access: There are authors who suggest the materials to be placed in an electronic repository $[1,20,19]$. Analysing the user perception in this study it was revealed that the users didn't want to be tied to a network connection to access online repositories. Hence having a learning content loaded into the application itself will be a guideline which takes advantage of the portability of mobile devices. This also enables access to materials with limited network connections.

b) Time independent access of materials: The learning materials should be anytime available for the learners. Having a native application, this could be attained where the learner will be able to access the learning resources on his convenience.

Support multiple device types A mobile application can have number of users having variety of mobile devices. Concept of BYOD (Bring your own device) highlights more personalized learning through the own device of the learner. Hence designers should have in mind about different screen sizes and different versions of operating systems.

Consider visual overload Visually overloaded application can distract the user from meeting the main purpose of m-learning to acquire knowledge. Through the user study it was also validated that the colour combinations should be appropriate and consistent across the apps.

\subsection{Pedagogical facets of designing m-learning}

Keep the information organized This principle discussed the factors of organizing the content pedagogically to fit a smaller screen through the means of simplification, chinking and grouping. These guidelines could be related to which was dis- 
cussed under Principle 01 - Technological facets of designing m-learning. Pedagogically, in a blended environment it is not possible to have the whole content of the course in the mobile application. But as a supporting medium, the learning could be enhanced through means of m-learning. This was addressed through our 2 nd research question of this study. Hence, we came up with the following guidelines which would be specific for m-learning content based on an e-learning course.

a) The m-learning application would best fit as a supporting medium of learning. Hence the content of the m-learning application should be organized in a way to highlight the most important sections of the whole course.

b) Creating smaller applications: Apart from presenting smaller information on the limited screen, it is also important to have the whole application comprising little information. When creating lessons based on an e-learning curriculum, the content can be really vast especially for a language learning application. In that case breaking the whole content into different smaller applications would be helpful to reduce the cognitive overload.

Multiple pedagogy/ activities Learning materials should also be designed in the form to accommodate different learning styles and characteristics [1]. Following guidelines were developed in our scenario based on this principle.

a) Consider multiple learning styles: Learners can vary from content based learners, problem based learning and collaborative learners. Hence having different types of events to cater different learning characteristics becomes important.

b) Include multiple activities: Having the same activities throughout the application might create boredom hence having multiple activities will help to keep the learners interactive. Activities may vary from multiple choices, short answers, fill in the blanks and drag and drop.

Design for supporting medium of learning Pedagogically, in a blended environment it is not possible to have the whole content of the course in the mobile application. But as a supporting medium, the learning could be enhanced through means of m-learning. This was addressed through our 2 nd research question of this study. Hence, we came up with the following guideline to support this principle.

a) The m-learning application would best fit as a supporting medium of learning. Hence the content of the m-learning application should be organized in a way to highlight the most important sections of the whole course.

\subsection{Human centered facets of designing m-learning}

Design for personalized learning The m-learning solution should comprise the means of personalization for the learner [21, 1, 19, 17], which is another main benefit attained through the provision of mobile devices.

a) Personalization through the application: The application should facilitate with a sense of personalization such as bookmarking which allows learners to organize 
the lessons according to their own preferences. Havin the own login of the user will allow to access the application throughout different devices with their own logins.

b) Personalization through the device: Learners should be able to access the lesson content through their own devices rather than having them through an external device.

Incorporate Collaborative activities It is advised by [17], that the mobile learning system should consider the relationship with other learners and systems. Space should be provided for the development of community of practice, apprenticeships and mentorships between learners and experts [17].

Keep the learners motivated Apart from the above discussed principles, we were able to come up with a need of keeping the learner engaged throughout the lessons. Learner motivation becomes a crucial component in mobile learning. We were able to present following guidelines to support this principle.

a) Learner should be able to know the current state of completion at any time: Throughout our experiments it was proven that having a method of showing the current state of the learner will motivate the leaner.

b) Game based learning should be a part of learning applications: Although this was not tested through our experiments, we were able to derive this through literature and the later requirements of our study [28]

\section{Conclusions}

The main contribution of this study is the design guidelines which could be used to create m-learning applications in a blended learning environment. The guidelines highlight the factors which needs to be considered when implementing an m-learning application on top of an existing e-learning curriculum.

The initial design principles identified through the literature was further extended through the analysis of data collected in this research. The artefact used for this purpose was put into evaluation among four groups in order to answer our research questions. The heuristic evaluation carried out with the subject matter experts and technical experts, showed that they were satisfied with Mobile4E and found it to be a useful tool, which could be introduced to the actual learner group. The comparative data gathered through the evaluation carried out with actual learners suggest that $\mathrm{m}$ learning could be effective when it is implemented in a blended learning environment along with other teaching and learning methods. The users of the course found this application to be highly useful and showed a strong positive attitude towards mlearning. The need of motivational factors in designing m-learning symbolizes the, measures to be taken to keep the learner engaged throughout the course period. Answering the second research question of the study we were able to conclude that mlearning would be more effective when implemented as a supporting medium of learning. 
The study confirms that the technological, pedagogical and human centered factors need to be considered as a whole while designing the application.

\section{$7 \quad$ Limitations and Future work}

Current study was based on deriving design guidelines and principles for developing m-learning applications in a blended learning environment. However, the evaluation was carried out using one artefact developed based on an existing e-learning content. Also, the curriculum used was extracted from the 'English for All' programme, which limits the study for specific settings. Hence justification of the findings independent of the content becomes challenging. Further evaluation might be required using different products in different settings to validate these guidelines. Another path of future study raised through the findings of this study would be experimenting the component of motivation to validate the design guidelines.

\section{Acknowledgements}

The first author would like to express her gratitude to the University of Colombo School of Computing (UCSC), Sri Lanka for facilitating to conduct this research work. We also convey our gratitude to the National Science Foundation, Sri Lanka for funding this research project.

\section{References}

[1] M. Ally, "Using learning theories to design instruction for mobile learning devices," UK, 2004.

[2] Gounder, "What is the potential impact of using mobile devices in higher education," in Proceedings of SIG GlobDev Fourth Annual Workshop, Shanghai, China, 2011.

[3] C. a. Valdes-Corbeil, "Are You Ready for Mobile Learning?," Educase , 2016.

[4] S. M. C. \&. H. K. Kim, "An Introduction to Current Trends and Benefits ofMobile Wireless Technology Use in Higher Education," 2006.

[5] D. Parsons, "A Mobile Learning Overview by Timeline and Mind Map," International Journal of Mobile and Blended Learning, vol. 6, no. 4, pp. 1-21, 2014 . https://doi.org/10.4018/ijmbl.2014100101

[6] S. Ekanayake and J. Wishart, "Identifying the potential of Mobile phone Camaras in Science Teaching and Leaning; A case study undertaken in Sri Lanka," International Journal of Mobile and Blended Learning, vol. 3, no. 2, pp. 16-30, 2011. https://doi.org/10.4018/jmb1.2011040102

[7] K. D. Gunawardana and S. Ekanayaka, "An Empirical Study of the Factors That Impact Medical Representatives" Attitude toward the Intention to Use M-Learning for Career Development," Sasin Journal of Management, vol. 15, no. 1, 2009.

[8] J.F.Fazeena, K.P.Hewagamage and A.Y.Ekanayaka, Enhance English language learning through M-learning extensions for professional development, Colombo : University of Colombo School of Computing, 2012. 
[9] H. Premadasa and R. Meegama, "Mobile Learning Environment with Short Messaging Service," PNCTM, vol. 1, pp. 95-99, 2012.

[10] K. Hewagamage, "“m-Learning Not an Extension of e-Learning" based on a Case Study of Moodle VLE," Beijing, China, 2011.

[11] K. H. Y. E. J.F. Fazeena, "A Theoretical Approach to Initiate Mobile Assisted Language Learning among School Leavers and University Students of Sri Lanka," in Australasian Conference on Information Systems, Adelaide, Australia, 2015.

[12] Y. E. J. F. Fazeena K.P. Hewagamage, "Designing an M-Learning Application for Mobile Assisted Language Learning," in The 9th IEEE International Conference on Ubi-Media Computing, 2016.

[13] Mobile4e, "Mobile4e," University of colombo school of computing, [Online]. Available: mobile4e.org . [Accessed 122 2017].

[14] e. centre, "English for all," Unviersity of colombo schoolof computing , [Online]. Available: http://www.e-learning.lk/efa/index.html. [Accessed 132 2017].

[15] D. Churchill and J. Hedberg, "Learning object design considerations for small-screen handheld devices," Computers \& Education, no. 50, p. 881-893, 2008. https://doi.org/10.1016/j.compedu.2006.09.004

[16] A. Herrington, J. Herrington and J. Mantei, "Design principles for mobile learning," in New technologies, new pedagogies:Mobile learning in higher education, Wollongong:, University of Wollongong, 2009, pp. 12-138.

[17] M. L. .. Koole, "A Model for Framing Mobile Learning," pp. 25-44.

[18] T. e. Guild, 158 Tips on mLearning: From Planning to Implementation, Santa Rosa, CA 95401: www.eLearningGuild.com, 2013.

[19] L.-H. Wong, "A learner-centric view of mobile seamless learning," British Journal of Educational Technology , vol. 43, no. 1, pp. 19-23, 2011. https://doi.org/10.1111/j.14678535.2011.01245.x

[20] T. Elias, "Universal Instructional Design Principles for Mobile Learning," The International Review of Research in Open and Distributed Learning, vol. 12, no. 2, 2011.

[21] L. F. Motiwalla, "Mobile learning: A framework and evaluation," Computers \& Education, vol. 49, p. 581-596, 2007. https://doi.org/10.1016/j.compedu.2005.10.011

[22] J. Herrington, S. McKenney, T. Reeves and R. Oliver, "Design-based research and doctoral students:Guidelines for preparing a dissertation proposal," 2007.

[23] D.-B. R. Collective, "Design-Based Research: An Emerging Paradigm for Educational Inquiry," Educational Researcher, vol. 32, no. 1, pp. 5-8, 2003. https://doi.org/10.3102/ 0013189X032001005

[24] W. Cotton, L. Lockyer and G. Brickell, "A Journey Through a Design-Based Research Project," Chesapeake, USA, 2009.

[25] T. Amiel and T. C. Reeves, "Design-Based Research and Educational Technology: Rethinking Technology and the Research Agenda," Educational Technology \& Society, vol. 11, no. 4, pp. 29-40, 2008.

[26] Google, "Bounce rate - About bounce rate," Google, [Online]. Available: https://support.google.com/analytics/answer/1009409?hl=en. [Accessed 106 2017].

[27] Bursten, "Realizing the potential of Mobile Phone Technology for Language learning," 2011.

[28] A. O. S. S. Mazeyanti Mohd Ariffin, "Evaluating Game-based Learning Effectiveness in Higher Education," Social and Behavioral Sciences, vol. 123, pp. 20-27, 2014.

[29] I. Karunaratne, "Teaching English in urban Sri Lanka-Some pedagogical issues.," 2003.

[30] E. E. P. I. 2015, "English language proficiency," EF- EPI, [Online]. Available: http://www.ef.co.nz/epi/regions/asia/sri-lanka/ . [Accessed 5 November 2016]. 
[31] H. Ratwatte, "Why Learn English? A comparative study of popular beliefs vs. belief of educated masses , Annual Academic session," Open University of Sri Lanka, 2011.

[32] P. a. Hulme, "Going with Grain: Mobile Devices in practice".

\section{Authors}

Mrs. F.Fazeena Jamaldeen is a lecturer/ course coordinator at Unitec Institute of Technology, New Zealand. She is reading for her Master of Philosophy (MPhil) with University of Colombo School of Computing, Sri Lanka.

Prof. K. P. Hewagamage is the director of University of Colombo School of Computing, Sri Lanka. He holds a bachelors degree in Computer Science with First Class honours form University of Colombo and a doctorate in Information Engineering from Hiroshima University, Japan.

Dr. A. Y. Ekanayake is a Senior Lecturer in Information Systems at the University of Colombo School of Computing (UCSC). She holds a bachelors degree in Information Systems and Management with First Class honours form Middlesex University, United Kingdom and a doctorate in Information Systems Brunel University, United Kingdom.

Article submitted 20 December 2017. Resubmitted 21 January 2018. Final acceptance 08 May 2018. Final version published as submitted by the authors. 